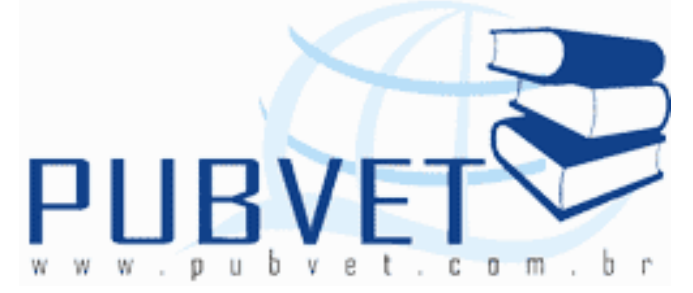

PUBVET, Publicações em Medicina Veterinária e Zootecnia.

\title{
Estimativa do rendimento potencial de azevém anual (Lolium multiflorum Lam.) através de modelos matemáticos
}

Newton de Lucena Costa $^{1}$, André Faé Giostri ${ }^{2}$, Ricardo Augusto de Oliveira ${ }^{3}$, Anibal de Moraes ${ }^{4}$

${ }^{1}$ Eng. Agr., M.Sc., Embrapa Roraima, Doutorando em Agronomia/Produção Vegetal, UFPR, Curitiba, Paraná. E-mail: newton@cpafrr.embrapa.br

${ }^{2}$ Eng. Agr., M.Sc., Doutorando em Agronomia/Produção Vegetal, UFPR, Curitiba, Paraná.

${ }^{3}$ Eng. Agr., D.Sc., Professor Adjunto, UFPR, Curitiba, Paraná. E-mail: rico@ufpr.br ${ }^{3}$ Eng. Agr., D.Sc., Professor Associado II, UFPR, Curitiba, Paraná. E-mail: anibalmr@ufpr.br

\section{Resumo}

Os modelos matemáticos para a predição do crescimento das pastagens apresentam potencial de uso para responder questões em científicas, agronômicas e de planejamento, auxiliando no entendimento sobre as interações genéticas, fisiológicas e do ambiente, como também nas decisões de práticas de manejo e na previsão de cenários. Existem vários métodos que permitem realizar o cálculo do rendimento potencial, sendo necessário correlacionar aqueles que melhor se ajustam as condições reais de campo, em função dos diversos fatores bióticos e abióticos que interferem no crescimento e desenvolvimento das plantas 
e, por conseguinte, no rendimento potencial. Dentre os metódos avaliados para a estimativa do rendimento de forragem do azevém anual (Lolium multiflorum Lam.), o que melhor se ajustou às condições de campo foi o proposto por Doorenbos e Kassam (1994), enquanto que o de Sinclair (1993) proporcionou estimativas do rendimento potencial da gramínea, passíveis de obtenção sob condições ambientais e práticas de manejo extremamente favoráveis. O método de Loomis e Williams (1963) estimou uma produtividade muito elevada, não havendo boa correlação com as condições reais de potencial de produção do azevém. A acurácia dos modelos em predizer o rendimento potencial foi diretamente proporcional a utilização de parâmetros que predigam de forma fidedigna a natureza abiótica e fisiológica dos fenômenos envolvidos no processo de acúmulo de biomassa.

Palavras-chave: modelagem, potencial de crescimento, pastagem, estratégias de manejo

\title{
Estimates of potential growth of annual rye grass (Lolium multiflorum Lam.) by mathematical models
}

\begin{abstract}
The mathematical models for the prediction of the pastures growth present potential of use for answer scientific, agronomic and planning questions, helping in the understanding about the physiological, genetic and environment interactions, as also in the decisions of management practices and in the scenery prevision. There are several methods to calculation the potential performance, however it's necessary correlate those more adjusted to real field conditions, in function of the diversity of biotics and abiotics factors that affect the growth and development of the plants and, consequently, in the forage yield potential performance. Among the methods evaluated for the estimate annual rye grass (Lolium multiflorum Lam.) forage potential performance, the methd proposed by
\end{abstract}


COSTA, N.L. et al. Estimativa do rendimento potencial de azevém anual (Lolium multiflorum Lam.) através de modelos matemáticos. PUBVET, Londrina, V. 5, N. 9, Ed. 156, Art. 1051, 2011.

Doorenbos and Kassam (1994) provided better adjusted to the field conditions, whereas the Sinclair (1993) method provided estimates of the grass growth potential, which can be obtained under extremely favorable environmental conditions and the utilization of better pasture management practices. The method of Loomis and Williams (1963) estimated a very highest productivity, and showed lower correlation with the real conditions for simulate rye grass growth potential. The acurate of the models in predict the potential performance was directly proportional to incorporates sensibility parameters that consider the prominent of abiotics and physiological phenomena involved in the biomass accumulation.

Keywords: modelling, growrh potential, pasture, management strategy

\section{Introdução}

O crescimento e o desenvolvimento das pastagens são modulados por fatores ambientais (radiação solar, água, temperatura e características físicas e químicas do solo), que podem ser otimizados com a adoção de práticas de manejo compatíveis com a manutenção do equilíbrio do ecossistema solo-plantaanimal (SINCLAIR, 1994). A influência dos fatores que limitam o rendimento de uma planta forrageira pode ser melhor compreendida a partir do conhecimento do rendimento potencial. A diferença entre o rendimento potencial e o comumente observado em sistemas reais de produção fornece a dimensão das perdas por estresses ambientais e biológicos que afetam a produtividade das pastagens (EVANS, 1983), permitindo intervenções para a sua maximização pelo uso de práticas de manejo que amenizem seus efeitos limitantes.

A integração de fatores determinantes da produtividade com os ambientais e suas variações estacionais permite entender e explicar a estacionalidade da produção das plantas forrageiras. A estimativa do rendimento potencial das pastagens tem sido realizada a partir de diferentes modelos, se tornando nos últimos anos uma importante ferramenta para a definição de prioridades de 
COSTA, N.L. et al. Estimativa do rendimento potencial de azevém anual (Lolium multiflorum Lam.) através de modelos matemáticos. PUBVET, Londrina, V. 5, N. 9, Ed. 156, Art. 1051, 2011.

pesquisa e a proposição de práticas de manejo para sistemas reais de produção, que expressem processos biológicos em modelos simplificadores das interrelações solo-planta-animal-clima, permitindo a previsão do comportamento da comunidade de plantas (DOURADO NETO et al., 1998). A maioria dos modelos utilizados baseia-se na simulação do crescimento de plantas e na previsão de rendimento, enfatizando a modelagem dos processos envolvidos na produção agrícola. A utilização desta técnica vem ganhando espaço, devido às inúmeras aplicações que os modelos possibilitam. Os modelos podem ser entendidos como uma simplificação ou uma representação do sistema real, baseando-se em hipóteses e propósitos definidos, ajudando numa melhor compreensão do sistema e com a possibilidade de serem aprimorados, a partir de modificações de modelos já existentes (SILVA, 1980).

Os modelos matemáticos para a predição do crescimento de pastagens apresentam potencial de uso para responder questões científicas, agronômicas e de planejamento, auxiliando no entendimento sobre as interações genéticas, fisiológicas e do ambiente, como também nas decisões de práticas de manejo, como aplicações de fertilizantes, irrigação, ajuste da pressão de pastejo, pela saída ou entrada de animais, diferimento, consorciação de gramíneas com leguminosas etc. (BOOTE et al., 1996). Modelos matemáticos baseados nos processos biológicos que permitem a compreensão das causas de respostas das plantas ao ambiente têm sido desenvolvidos para as principais culturas, sendo denominados de matemáticos-fisiológicos, apresentando uma série de vantagens, pois a) informações sobre os diferentes processos podem ser reunidas em um único modelo, permitindo uma visão global da cultura; b) resume convenientemente grande quantidade de informações; c) a base matemática para as hipóteses adotadas permite compreender quantitativamente a natureza das interaçõs ambiente-planta; d) a modelagem estimula novos paradigmas e pressuposições, detectando áraes onde o conhecimento é limitado e, f) modelos permitem interpolaões e previsões (PEREIRA; MACHADO, 1986; PLÁ; LOPES, 

através de modelos matemáticos. PUBVET, Londrina, V. 5, N. 9, Ed. 156, Art. 1051, 2011.

1998). Apesar das limitações apresentadas pelos modelos, que podem ser corrigidas em parte por alguns ajustes, notadamente a inclusão de parâmetros ambientais e fisiológicos que contribuam para sua maior acurácia, estes se constituem numa ferramenta útil para estimar o rendimento potencial, com o intuito de auxiliar na identificação dos fatores que podem afetar negativamente 0 rendimento, bem como na tomada de decisão sobre ações de manejo.

Dentre os recursos forrageiros usados na estação fria, o azevém anual (Lolium multiflorum Lam.) é a gramínea com maior área cultivada na região Sul, em decorrência de sua fácil implantação, utilização, elevado potencial produtivo e versatilidade, podendo ser utilizado como pastagem cultivada de inverno, para o melhoramento de pastagens nativas ou como cobertura de solo visando ao plantio direto na primavera.

Neste trabalho foi estimado o rendimento potencial de azevém anual ( $L$. multiflorum Lam.), a partir de três modelos, bem como discutido os fatores relevantes e as limitações que interferem no processo de predição para a obtenção do rendimento potencial.

\section{Metodologia}

Os cálculos do rendimento potencial foram realizados a partir de três modelos: Loomis e Williams (1963), Sinclair (1993) e Doorenbos e Kassam (1994). Os valores estimados foram comparados com aqueles obtidos por Ribeiro et al. (2009), em Curitiba, Paraná, avaliando pastagens de azevém sob pastejo contínuo de cordeiros, durante o período de agosto a dezembro de 2004. A carga animal foi variável, em função da disponibilidade de forragem, sendo os ajustes realizados a intervalos de 14 dias. O solo da área experimental é classificado como Latossolo Vermelho-Amarelo Álico (EMBRAPA, 1999), textura argilosa, campo subtropical e relevo suave ondulado. O ambiente de produção foi adequado ao plantio do azevém, tendo o solo apresentado as seguintes 
características químicas: $\mathrm{pH}=6,3 ; \mathrm{P}=12,8 \mathrm{mg} / \mathrm{dm}^{3} ; \mathrm{K}=0,14 \mathrm{cmol} / \mathrm{dm}^{3} ; \mathrm{Ca}=$ $7,26 \mathrm{cmol}_{\mathrm{c}} / \mathrm{dm}^{3} ; \mathrm{Ca}^{2}+\mathrm{Mg}^{2}=10,9 \mathrm{cmol}_{\mathrm{c}} / \mathrm{dm}^{3}$ e saturação de bases de $72 \%$. A adubação de manutenção constou da aplicação de $300 \mathrm{~kg} \mathrm{~N} / \mathrm{ha}$, parcelada em três vezes, nos meses de maio, junho e agosto.

Os dados de temperatura, insolação, nebulosidade e radiação solar foram coletados junto a Estação Climatológica do Instituto Nacional de Meteorologia localizada em Curitiba (923 m de altitude, 25042'de latitude sul e 49027'de longitude oeste). O coeficiente de extinção luminosa, o índice de área foliar (IAF) e a eficiência de utilização da radiação (EUR) foram estimados a partir dos dados reportados por Pontes et al. (2003, 2004), Cauduro et al. (2006) e Pellegrini et al. (2010) para pastagens de azevém submetidas a diferentes práticas de manejo. Para o cálculo do modelo proposto por Doorenbos e Kassam (1994) foi utilizada a temperatura média de $17,3^{\circ} \mathrm{C}$. Como as amostras para a estimativa da disponibilidade de forragem foram realizadas ao nível do solo, o índice de colheita para os modelos propostos por Loomis e Williams (1963) e Sinclair (1993) foi considerado como $100 \%$.

\section{Comparação dos métodos na estimativa dos rendimentos potenciais e comparação com produtividades reais}

As estimativas da produtividade de forragem apresentaram grandes variações, o que pode ser atribuído à robustez dos parâmetros utilizados por cada modelo matemático, em predizer o rendimento potencial (Tabela 1, 2, 3 e 4). 0 método de Loomis e Williams utiliza apenas a radiação solar incidente como parâmetro de entrada, implicando na predição do maior rendimento total de forragem ( $54.716 \mathrm{~kg}$ de MS/ha), o qual dificilmente será obtido em condições de campo, mesmo sob condições bióticas e abióticas extremamente favoráveis. 0 método preconiza a linearidade entre a interceptação da radiação e a produtividade de MS, em condições ambientais extremamente favoráveis, 
contudo, desconsidera aspectos importantes relacionados à planta, tais como arquitetura das folhas, IAF, coeficiente de extinção luminosa $\left(C_{K}\right)$, temperatura e EUR. Apesar das limitações, sua acurácia poderá ser aumentada com a determinação, para cada ambiente e cultura, das perdas por albedo e do consumo de energia pela respiração. O método proposto por Sinclair estimou uma produtividade de forragem 49\% inferior $(26.999 \mathrm{~kg}$ de MS/ha), comparativamente à calculada pelo método de Loomis e Williams, como decorrência da utilização de outros parâmetros relacionados com a estrutura da pastagem (IAF e $C_{k}$ ), tornando a predição mais fidedigna. O método de Doorenbons e Kassam foi o que apresentou maior correlação com as condiçoes reais, estimando um rendimento de $9.530 \mathrm{~kg}$ de $\mathrm{MS} / \mathrm{ha}$, enquanto que sob condições reais foi obtida uma produtividade de $9.066 \mathrm{~kg}$ de MS/ha. O método considera aspectos fisiológicos relativos à cultura (IAF, perdas por respiração) e ao ambiente (radiação incidente, temperatura, fotoperíodo e nebulosidade), o que aumenta sua acurácia na predição do rendimento potencial. Considerando-se a distribuição mensal do rendimento de forragem, o método de Loomis e Williams e o de Sinclair apresentaram tendências semelhantes, às observadas para o rendimento total, enquanto que para o de Doorenbos e Kassam, as estimativas referentes aos meses de agosto e setembro foram inferiores à constatada experimentalmente; a de outubro foi semelhante e as de novembro e dezembro superiores (Figura 1). Como o modelo desconsidera o efeito do animal sobre a persistência da pastagem, durante a estação de pastejo, o manejo utilizado, independentemente das condições ambientais favoráveis, contribuiu para a redução do rendimento de forragem, considerando-se a fisiologia do crescimento e o ciclo anual do azevém. 
COSTA, N.L. et al. Estimativa do rendimento potencial de azevém anual (Lolium multiflorum Lam.) através de modelos matemáticos. PUBVET, Londrina, V. 5, N. 9, Ed. 156, Art. 1051, 2011.

Tabela 1. Cálculo do rendimento potencial de forragem de azevém pelo método de Loomis e Williams (1963).

\begin{tabular}{|c|c|c|}
\hline Componentes do Cálculo & Valor de Entrada & Valor Calculado \\
\hline Radiação solar incidente média & $416 \mathrm{cal}^{\mathrm{cm}} \mathrm{cm}^{2} \cdot \mathrm{dia}^{-1}$ & \\
\hline Caloria da radiação solar visível & 8,64 $\mu$ Einstens.cal ${ }^{-1}$ & \\
\hline Energia bruta para fotossíntese & & 3.594, $24 \mu$ Einstens. cal ${ }^{-1}$ \\
\hline Perda por albedo (24\%) & $862,62 \mu$ Einstens.cal $^{-1}$ & \\
\hline Perda por absorção inativa (10\%) & $359,42 \mu$ Einstens.cal ${ }^{-1}$ & \\
\hline Energia líquida para fotossíntese & & 2.372,14 $\mu$ Einstens.cal ${ }^{-1}$ \\
\hline Necessidade de quantum & 10 quanta.molécula $\mathrm{CO}_{2}$ reduzida $^{-1}$ & \\
\hline Produção bruta de $\mathrm{CH}_{2} \mathrm{O}$ & & $237,22 \mu$ moles.cm ${ }^{2} \cdot \mathrm{dia}^{-1}$ \\
\hline Consumo da respiração (40\%) & & $94,88 \mu$ moles.cm ${ }^{2} \cdot \mathrm{dia}^{-1}$ \\
\hline Produção líquida de $\mathrm{CH}_{2} \mathrm{O}$ & $30 \mathrm{~g} \cdot \mathrm{mol}^{-1}$ & $42,70 \mathrm{~g} \cdot \mathrm{m}^{2} \cdot \mathrm{dia}{ }^{-1}$ \\
\hline Matéria seca total (MST) & & $70.149 \mathrm{~kg} \cdot \mathrm{ha}^{-1}$ \\
\hline Ciclo da cultura & 150 dias & \\
\hline MST referente à parte aérea & $70 \%$ & \\
\hline Índide de colheita & $100 \%$ & \\
\hline Nutrientes inorgânicos & $8 \%$ & \\
\hline Rendimento de matéria seca & & $54.716 \mathrm{~kg} \cdot \mathrm{ha}^{-1}$ \\
\hline
\end{tabular}

Tabela 2. Cálculo do rendimento potencial de forragem do azevém pelo método de Sinclair (1993).

\begin{tabular}{lcc}
\hline Componentes do Cálculo & Valor de Entrada & Valor Calculado \\
\hline Radiação solar incidente média & $416 \mathrm{cal} \cdot \mathrm{cm}^{2} \cdot \mathrm{dia}{ }^{-1}$ & $17,4117 \mathrm{MJ} \cdot \mathrm{m}^{2} \cdot \mathrm{dia}^{-1}$ \\
Eficiência de uso da radia ção (EUR) & $1,5 \mathrm{~g} \cdot \mathrm{MJ}^{-1}$ & \\
Coeficiente de extinção (K) & 0,5 & \\
Índidce de área foliar (IAF) & 4,1 & 0,8713 \\
Fração da radiação solar interceptada & & $15,171 \mathrm{MJ}^{2} \mathrm{~m}^{2} \cdot \mathrm{dia}^{-1}$ \\
Radiação interceptada & & $22,755 \mathrm{~g}^{2} \mathrm{mia}^{-1}$ \\
Taxa de crescimento da cultura (TCC) & & $3.423,3 \mathrm{~g} \cdot \mathrm{m}^{2}$ \\
Matéria seca total (MST) & $150 \mathrm{dias}$ & $3.857 \mathrm{~g} \cdot \mathrm{m}^{2}$ \\
Ciclo da cultura & $70 \%$ & \\
MST referente à parte aérea & $100 \%$ & $\mathbf{2 6 . 9 9 9} \mathbf{~ k g} \cdot \mathrm{ha}^{-1}$ \\
Índice de colheita & & \\
\hline Rendimento de matéria seca & &
\end{tabular}


COSTA, N.L. et al. Estimativa do rendimento potencial de azevém anual (Lolium multiflorum Lam.) através de modelos matemáticos. PUBVET, Londrina, V. 5, N. 9, Ed. 156, Art. 1051, 2011.

Tabela 3. Cálculo do rendimento potencial do azevém pelo método de Doorenbos e Kassam (1994).

\begin{tabular}{lc}
\hline Componentes do Cálculo & Valor Calculado \\
\hline Produção Bruta com nuvens (PPBn) & $51,9 \mathrm{~kg} \cdot \mathrm{ha}^{-1} \cdot \mathrm{dia}^{-1}$ \\
Produção Bruta sem nuvens (PPBc) & $171,7 \mathrm{~kg} \cdot \mathrm{ha}^{-1} \cdot \mathrm{dia}^{-1}$ \\
Produção Bruta de matéria seca (PPBp) & $223,6 \mathrm{~kg} \cdot \mathrm{ha}^{-1} \cdot \mathrm{dia}^{-1}$ \\
Radiação solar incidente média (Q) & $416 \mathrm{cal} \cdot \mathrm{cm}^{2} \cdot \mathrm{dia}^{-1}$ \\
Correção para temperatura de dias nublados (cTn) & 1,06 \\
Correção para temperatura de dias claros (cTc) & 1,11 \\
Correção para IAF (CIAF) & 0,49 \\
Correção para respiração (Cr) & 0,60 \\
Correção para parte colhida (Cc) & 1,00 \\
\hline Rendimento de Matéria Seca & $\mathbf{9 . 5 3 0 ~} \mathbf{k g} \cdot \mathbf{h a}^{-1}$ \\
\hline
\end{tabular}

Tabela 4. Rendimento potecial de forragem ( $\mathrm{kg}$ de MS/ha) de azevém calculado por três modelos matemáticos, comparativamente ao rendimento experimental reportado por Ribeiro et al. (2009), em Curitiba, Paraná.

\begin{tabular}{|c|c|c|c|}
\hline $\begin{array}{c}\text { Loomis e Williams } \\
(1963)\end{array}$ & Sinclair (1993) & $\begin{array}{c}\text { Doorenbos e Kassam } \\
(1994)\end{array}$ & Ribeiro et al. (2009) \\
\hline 54.716 & 26.999 & 9.530 & 9.066 \\
\hline
\end{tabular}

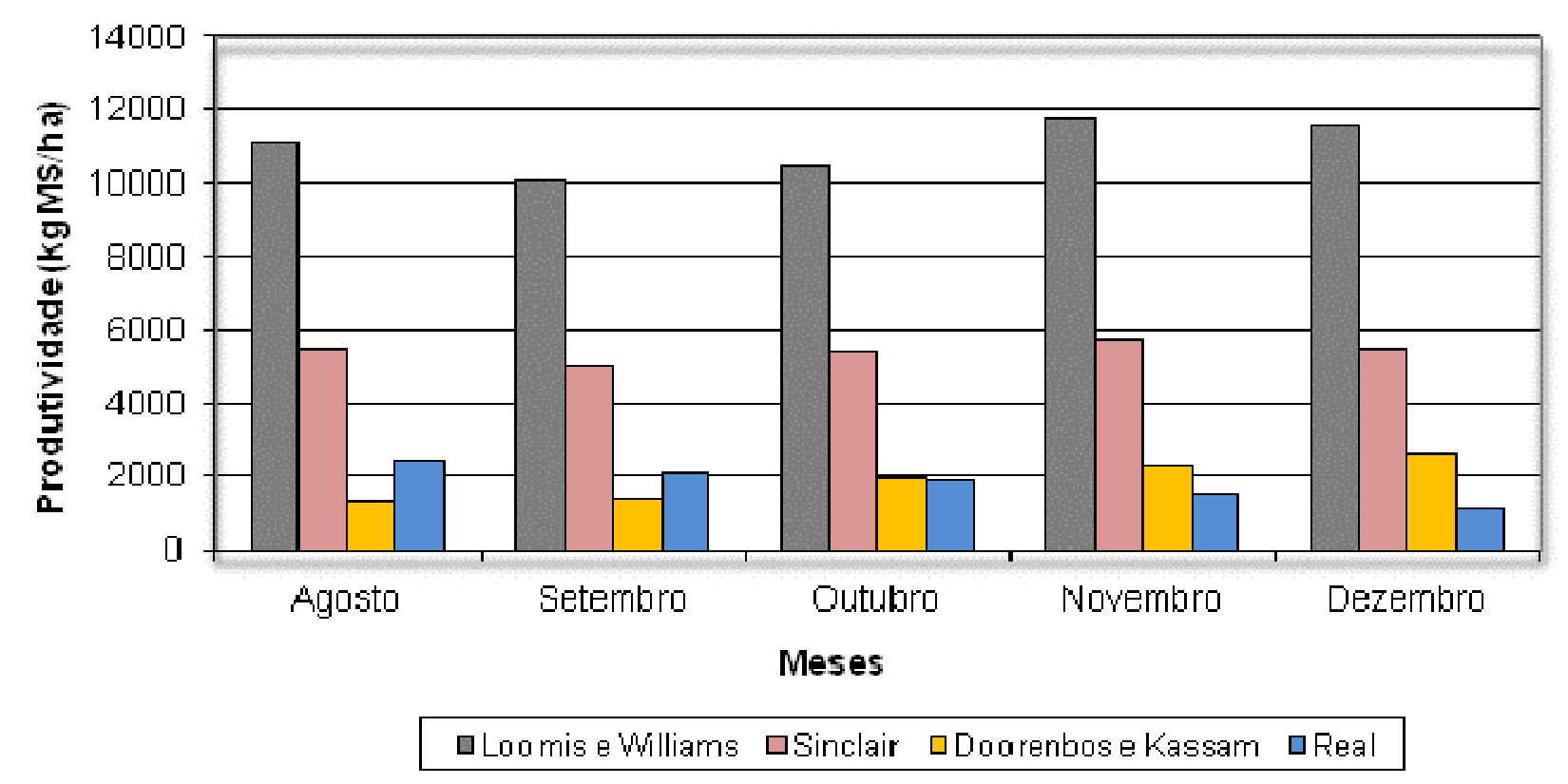

Figura 1. Rendimento potencial e real de forragem de azevém, em função dos métodos de estimativa e do período de utilização da pastagem. 
Os rendimentos experimentais do azevém são variáveis e diretamente afetados pelas práticas de manejo impostas e pelas condições ambientais. Barbosa et al. (2007) reportaram rendimentos de MS de 10.767 e 10.498 kg/ha, respectivamente para pastagens submetidas a intensidades de pastejo moderada (plantas rebaixadas até $12 \mathrm{~cm}$ e oferta diária de 9,67 kg de MS/100 kg de peso) e baixa (plantas rebaixadas a $18 \mathrm{~cm}$ e oferta diária de $18,28 \mathrm{~kg}$ de MS/100 kg de peso vivo). Avaliando sistemas de manejo do azevém, Cauduro et al. (2006) estimaram rendimentos de 2.297; 2.983; 3.545 e $1.736 \mathrm{~kg}$ de MS/ha, respectivamente para a utilização de pastejo contínuo ou rotacionado e intensidades de pastejo baixa ou moderada. Carvalho et al. (2010), avaliando pastagens de azevém manejadas em quatro alturas sob lotação contínua, constataram rendimentos de 9.210; 7.270; 8600 e $7.760 \mathrm{~kg}$ de MS/ha, respectivamente para intensidades de desfolhação de 10, 20, 30 e $40 \mathrm{~cm}$. Em ensaios de avaliação de populações de azevém, os rendimentos oscilaram de 3.600 a 8.500 kg/ha, em Minas Gerais (PEREIRA et al., 2008) e 1.240 a 6.350 kg/ha no Rio Grande do Sul (MITTELMANN et al., 2005; FLORES et al., 2008). Para pastagens de azevém fertilizadas com nitrogênio ( $N$ ), Pellegrini et al. (2010) reportaram rendimentos de 4.203; 5.696; 6.851 e $7.778 \mathrm{~kg}$ de MS/ha, respectivamente para doses de $0,75,150$ e $225 \mathrm{~kg}$ de N/ha.

\section{Fatores que determinam o rendimento e as limitações ao rendimento potencial}

A produtividade e a perenidade da pastagem decorrem de sua capacidade de reconstituição de nova área foliar, após o pastejo, a qual está estreitamente relacionada com as condições ambientais, como umidade e fertilidade do solo, temperatura, radiação solar, características genéticas da planta forrageira e as 
COSTA, N.L. et al. Estimativa do rendimento potencial de azevém anual (Lolium multiflorum Lam.) através de modelos matemáticos. PUBVET, Londrina, V. 5, N. 9, Ed. 156, Art. 1051, 2011.

práticas de manejo da pastagem. As condições do ambiente são determinantes no processo de formação e manutenção dos tecidos vegetais e, consequentemente, da formação da área foliar.

\section{1 Água}

A água é o principal veículo de transporte de nutrientes para todas as partes da planta, conferindo turgidez aos tecidos e mantendo em equilíbrio a sua temperatura da planta (GALETI, 1982). Muitos processos fisiológicos na planta como a expansão e o alongamento de folhas, a abertura e fechamento estomático e a fotossíntese são regulados pela pressão de turgescência das células (TAIZ; ZEIGER, 2004). O consumo de água pelas plantas forrageiras é determinado pela demanda evaporativa da atmosfera, tipo de solo e pelas características da planta (área foliar, distribuição e profundidade do sistema radicular), além de sua habilidade em utilizar a água armazenada no solo e a capacidade de controlar as perdas pelo mecanismo estomático (MATZENAUER; SUTILI, 1983). A expansão foliar é um dos processos fisiológicos mais sensíveis a deficiência hídrica. A planta cessa o alongamento de folhas e raízes muito antes dos processos de fotossíntese e divisão de células serem afetados. A evapotranspiração potencial da pastagem geralmente excede a precipitação pluvial, de modo que a real é aproximadamente igual à precipitação, o que torna a água o fator isolado que mais limita a produção primária (TIESZEN; DETLING, 1983). O comportamento de uma planta cultivada, em situação de déficit hídrico, dependerá do estádio de desenvolvimento, do genótipo e da duração e severidade da restrição hídrica (PETRY et al., 1999).

A quantidade de água absorvida e transportada está diretamente relacionada com a quantidade de energia solar interceptada, constituindo-se em um mecanismo eficiente de dissipação de calor, evitando o dessecamento foliar e assegurando temperaturas adequadas para a realização dos processos 

através de modelos matemáticos. PUBVET, Londrina, V. 5, N. 9, Ed. 156, Art. 1051, 2011.

metabólicos internos da planta (LEMAIRE, 2001). Em algumas circunstâncias, as plantas podem ser beneficiadas com o sombreamento, como resultado de redução na demanda de água. A maior umidade do solo deve ser ajustada com o aumento do número de pastejos, pois a aceleração do desenvolvimento da planta forrageira acarreta declínio nos teores de proteína bruta e elevação dos de fibra, reduzindo o consumo de forragem pelos animais

Em ecossistemas de pastagens, a produtividade de forragem é regulada pela assimilação e alocação de carbono e $\mathrm{N}$ e pela evapotranspiração. Desta forma, além de afetar os processos fisiológicos e as características morfogênicas e estruturais da gramínea, o estresse hídrico pode prejudicar o crescimento da pastagem ao reduzir a absorção de $\mathrm{N}$ e de outros nutrientes (RODRIGUES; RODRIGUES, 1987). Ainda que o manejo de fatores abióticos, como água e nutrientes, provoque respostas da pastagem consideravelmente importantes, a magnitude dessas respostas é altamente dependente do controle da desfolhação. Para Panicum maximum cv. Tobiatã, Dias Filho (1996) reportou uma correlação negativa entre a expansão de folhas e o nível de umidade do solo, a qual foi reduzida em $60 \%$ quando a gramínea foi submetida a déficit hídrico moderado. Em pastagens de azevém, Freitas et al. (2003) constataram que a utilização de lâminas de irrigação de 2 e $5 \mathrm{~cm}$ proporcionou incrementos de 159 e 265\% para o crescimento de raízes; 19 e 103\% para a matéria seca (MS) de raízes e, 78 e $125 \%$ para a MS da parte aérea, respectivamente, comparativamente à pastagem não irrigada.

\subsection{Temperatura}

A temperatura constitui importante fator abiótico determinante da distribuição, da adaptabilidade e da produtividade das plantas, em função de sua capacidade em manter a fotossíntese líquida sob temperaturas supraótimas, ou acima do ótimo requerido para a fotossíntese líquida máxima. A temperatura é 
COSTA, N.L. et al. Estimativa do rendimento potencial de azevém anual (Lolium multiflorum Lam.) através de modelos matemáticos. PUBVET, Londrina, V. 5, N. 9, Ed. 156, Art. 1051, 2011.

um dos fatores ambientais com efeito imediato sobre os processos bioquímicos (respiração e fotossíntese), físicos (transpiração) ou morfogênicos das plantas (LEMAIRE; AGNUSDEI, 2000). As temperaturas durante o dia devem ser ótimas para fotossíntese e o acúmulo líquido de biomassa, enquanto à noite, as temperaturas mais baixas conservam energia por meio da redução do metabolismo respiratório. O crescimento da planta deve-se ao aumento da temperatura que proporciona mudanças bioquímicas nas células, com elevação na taxa de crescimento foliar. Em temperaturas muito baixas a redução no crescimento tem como causa a diminuição na assimilação de $\mathrm{CO}_{2}$. A temperatura estabelece uma forte interação com a radiação luminosa e influencia de forma acentuada e imediata o crescimento da folha, limitando a divisão e o alongamento das células, condicionando a sua eficiência fotossintética, notadamente em elevados níveis de radiação luminosa, o que reflete em diferentes curvas de resposta do crescimento, em função da temperatura do ar das gramíneas forrageiras (HODGSON, 1990).

A temperatura influencia na qualidade da forrageira, pois sob altas temperaturas as forrageiras apresentam maior proporção de parede celular e menor digestibilidade, além do aumento na lignificação da parede celular (WILSON, 1982; VAN SOEST, 1994). A temperatura afeta a velocidade de aparecimento das folhas, pois se trata de um atributo termo-dependente. As variações da temperatura ao longo do dia demandam contínuos ajustes da planta, de modo a manter a produtividade fotossintética de suas folhas. As espécies forrageiras de clima tropical produzem muito pouco quando expostas a temperaturas menores que $16^{\circ} \mathrm{C}$ (WHITHMAN, 1980).

A temperatura sob a qual a planta se desenvolve tem maior influência sobre a taxa de alongamento de folhas do que sobre sua taxa de aparecimento (MARASCHIN, 1995), podendo ter sua taxa de alongamento foliar aumentada (GASTAL et al., 1992). Bahmani et al. (2000) observaram crescimento exponencial do perfilhamento com o aumento dos graus-dia, porém no 
tratamento sombreado ( $15 \%$ da radiação fotossinteticamente ativa) esse crescimento foi linear, sendo que foi possível perceber uma diferença significativa entre grupos genéticos $x$ tratamentos de luz $x$ graus-dia $x$ número de perfilhos por planta estudada (Lolium perenne cvs. Ellet e Grasslands Ruanui). A temperatura ótima para o máximo crescimento está ao redor de 18 a $20^{\circ} \mathrm{C}$. O crescimento é paralisado com temperaturas baixas, apresentando baixo desempenho produtivo no inverno e, mesmo mantendo as folhas verdes, é sensível a geadas fortes.

\subsection{Radiação Solar}

A radiação solar é a fonte primária de toda a energia que mantém a ecosfera do planeta, a qual é convertida em energia química através da fotossíntese, processo físico-químico onde são sintetizados compostos orgânicos a partir de matéria-prima inorgânica, na presença de luz solar (LARCHER, 1975). A produção forrageira se baseia na transformação de energia solar em compostos orgânicos pela fotossíntese, onde o dióxido de carbono da atmosfera é combinado com a água e convertido em carboidratos com a utilização da energia solar. A produtividade primária de uma pastagem é determinada basicamente pela quantidade de carbono acumulada por unidade de área de solo, por unidade de tempo. O carbono é o principal constituinte dos tecidos vegetais e a taxa de acúmulo de biomassa de um pasto é determinada pela taxa com que o nutriente é assimilado pelas plantas (LEMAIRE; CHAPMAN, 1996).

A radiação influi significativamente na taxa de alongamento das hastes. Admite-se que as maiores taxas de alongamento ocorrem sob condições de primavera e verão, quando as temperaturas máximas e mínimas atingem $33 / 28^{\circ} \mathrm{C}$ e $27 / 22^{\circ} \mathrm{C}$, respectivamente. Nas condições de outono, o máximo de alongamento das hastes ocorre com temperaturas de $27 / 22^{\circ} \mathrm{C}$, havendo decréscimos se as temperaturas atingem $33 / 28^{\circ} \mathrm{C}$ (FERRARIS et al., 1986). 
COSTA, N.L. et al. Estimativa do rendimento potencial de azevém anual (Lolium multiflorum Lam.) através de modelos matemáticos. PUBVET, Londrina, V. 5, N. 9, Ed. 156, Art. 1051, 2011.

A captação da radiação incidente pelas culturas depende do seu IAF, posição solar, geometria e tamanho da folha, ângulo de inserção, idade, arranjo das plantas, época do ano e nebulosidade (VARLET-GRANCHER et al., 1989) e ainda da espécie cultivada e de práticas de manejo na cultura. Se o IAF aumentar muito, a produção de MS não acompanhará, porque haverá grande quantidade de folhas basais sombreadas e folhas velhas que serão menos eficientes fotossinteticamente. Além da quantidade de luz, outro aspecto importante da luz diz respeito à sua qualidade, especificamente à relação V/Ve (vermelho/vermelho extremo) da luz incidente em cada camada de folhas. A ativação de gemas e a produção de novos perfilhos são dadas por esta relação $V / V e$ da radiação incidente, relação essa que é reduzida à medida que se aumenta a área foliar do dossel (MATTHEW et al., 2000). Provavelmente, devido a isso, a produção de novos perfilhos pára antes da área foliar de equilíbrio ser alcançada. Gautier et al. (1999) estudando duas cultivares de azevém perene (L. perenne L.) observou que a diminuição da relação $V /$ Ve reduziu o índice de perfilhamento por reduzir o site filling, ao passo que a diminuição da luz azul não teve efeito significativo no perfilhamento. As respostas de perfilhamento ao fluxo de fótons fotossintéticos e a relação $V / V e$ foram semelhantes nas duas cultivares selecionadas para contrastar o comprimento de folha curta e longa.

A eficiência do uso da radiação pelas plantas depende da interação entre a vegetação e o ambiente, que define como os processos de fotossíntese e transpiração serão afetados pelos elementos climáticos e edáficos ou como a estrutura do dossel afeta a quantidade de radiação incidente que atinge os seus diferentes estratos e sua absorção pelas plantas (RUSSELL et al., 1989). A relação entre a produção de MS e a quantidade de RFA interceptada ou absorvida tem sido amplamente usada para definir a eficiência de uso da radiação pelas culturas (SIVAKUMAR; VIRMANI, 1984; COSTA et al., 1996). Em condições não limitantes, vários autores demonstraram a linearidade da relação entre a MS total acumulada e a disponibilidade da RFA (BISCOE et al. 1975; MONTEITH, 1965, 
COSTA, N.L. et al. Estimativa do rendimento potencial de azevém anual (Lolium multiflorum Lam.) através de modelos matemáticos. PUBVET, Londrina, V. 5, N. 9, Ed. 156, Art. 1051, 2011.

1977; GALLAGHER; BISCOE, 1978; BONHOMME, 2000; SCHÖFFEL; VOLPE, 2001; SILVA JÚNIOR et al., 2009), mormente quando se considera a comunidade de plantas e não a folha isoladamente. Posteriormente o modelo proposto foi utilizado para caracterizar o comportamento individual e em conjunto de várias espécies $\left(\mathrm{C}_{3}\right.$ ou $\mathrm{C}_{4}$ ), em termos de potencial para um dado ambiente (GOSSE et al., 1986). Entretanto, nem sempre o aumento linear de MS, em função da radiação interceptada, resulta em aumentos lineares de produtividade (SHIBLES; WEBER, 1965, 1966; SCHÖFFEL; VOLPE, 2001), evidenciando que há outros fatores relacionados com a produtividade, como potencial genético e disponibilidade de água e nutrientes.

O fluxo de energia dentro do sistema pastoril compreende o captura inicial da energia solar pela vegetação, que a converte em energia química pela fotossíntese nas células clorofiladas das plantas. A ingestão da vegetação pelos herbívoros determina a conversão da energia capturada pelas plantas em produto animal. Na ausência de herbívoros, a energia capturada e transformada pelas plantas é transferida para os decompositores após a senescência. 0 funcionamento do ecossistema pastagem é caracterizado por fluxos de energia (radiação, calor sensível) e de massa $\left(\mathrm{CO}_{2}, \mathrm{H}_{2} \mathrm{O}, \mathrm{N}\right.$, minerais) entre as plantas de uma comunidade, o solo e atmosfera (LEMAIRE, 2001), representados pelos diferentes processos fisiológicos de captação de energia e nutrientes. Esses fluxos são influenciados pelas características estruturais da população de plantas, em termos de tamanho e distribuição espacial das superfícies de troca, como área foliar e distribuição radicular. A interação entre plantas e seu ambiente externo é regulada por fatores fisiológicos, como a difusão estomática de $\mathrm{CO}_{2}$ e água, fotossíntese e respiração, absorção do nitrato ou fixação de N (TAIZ; ZEIGER, 2004).

O papel fundamental da radiação solar decorre de que mais de $90 \%$ do peso seco das plantas provém diretamente da assimilação fotossintética do carbono. A fração mineral absorvida do solo pelas raízes representa apenas 6 a 
9\% do peso seco total da planta. Neste contexto, o conhecimento do processo da fotossíntese das comunidades vegetais e os fatores que a afetam, torna-se primordial para a otimização da produtividade primária do ecossistema.

A capacidade produtiva de biomassa de um sistema pastoril pode parecer ilimitada considerando-se o imenso e contínuo suprimento de energia solar. Entretanto, a produtividade primária (biomassa vegetal/área/tempo) é muito baixa na maioria dos ecossistemas naturais ou cultivados. A produtividade primária é limitada basicamente por duas categorias de restrições ecológicas. A primeira restrição diz respeito à qualidade da radiação solar que atinge a superfície da terra. Apenas $45 \%$ desta energia estão dentro do espectro da radiação que é efetivo para a fotossíntese (RFA = radiação fotossinteticamente ativa compreendida na faixa de comprimentos de onda entre 400 a $700 \mathrm{~nm}$ ). Os restantes $55 \%$ do espectro não são convertidos em energia química, não formando biomassa. No entanto, esta fração é importante para o ecossistema ao ser absorvida na forma de energia calórica pela atmosfera, solo e vegetação, gerando o ambiente térmico necessário às reações de síntese e para funcionamento do ciclo hidrológico e de nutrientes. A segunda categoria de restrições ecológicas que limitam a produtividade primária envolve a disponibilidade de outros fatores abióticos cujo nível pode impedir a máxima captação da energia solar. Água, temperatura e nutrientes frequentemente limitam o desenvolvimento da área de folhas necessária para a máxima captação da radiação fotossinteticamente ativa incidente (NABINGER, 1997, 2001).

\subsection{Nutrientes}

A produtividade de uma pastagem de gramíneas depende de vários fatores, como condições climáticas, edáficas e manejo a que são submetidas, principalmente em relação ao nível de $\mathrm{N}$, por tratar-se do nutriente mais limitante ao crescimento das plantas (CHAPIN et al., 1987), cuja deficiência afeta 
COSTA, N.L. et al. Estimativa do rendimento potencial de azevém anual (Lolium multiflorum Lam.) através de modelos matemáticos. PUBVET, Londrina, V. 5, N. 9, Ed. 156, Art. 1051, 2011.

negativamente a fotossíntese, reduzindo a síntese e atividade da enzima responsável pela assimilação do $\mathrm{CO}_{2}$ (Rubisco) (MAKINO et al., 1984). Alterações deste tipo podem ter significado bastante expressivo em termos práticos, podendo-se obter respostas lineares de rendimento de MS até o nível de $300 \mathrm{~kg}$ N/ha, em gramíneas sob lotação contínua (SOARES, 1999). Por outro lado, o N é o insumo de custo mais elevado nas pastagens cultivadas de inverno. Segundo Restle et al. (1999), a adubação nitrogenada (445 kg de uréia/ha) representou $41,77 \%$ da composição dos custos para implantação e uso da pastagem de aveia preta mais azevém. Para a mistura de triticale com azevém, Soares (1999) cita que a adubação nitrogenada (389 kg de uréia/ha) representou 39,86\% do custo total da pastagem. Quando há uma adequada oferta de $\mathrm{N}$ no solo, a sua maior absorção pela gramínea afeta positivamente a produtividade de forragem, contudo, não se observa um incremento linear no seu conteúdo de $\mathrm{N}$, como conseqüência do declínio da quantidade de $\mathrm{N}$ absorvida por unidade de biomassa adicional (GREENWOOD et al., 1990; LEMAIRE; SALETTE, 1984). A absorção e alocação de $\mathrm{N}$ entre os diversos compartimentos da planta contribuem para $\mathrm{O}$ entendimento dos processos que governam o fluxo de $\mathrm{N}$ e suas relações com à qualidade ambiental e à qualidade do produto, pois a absorção e acumulação de $\mathrm{N}$ nos cultivos representam os dois maiores componentes do ciclo do $\mathrm{N}$ no agroecossistema (LUSTOSA, 2002).

Algumas características estruturais podem ser modificadas conforme a disponibilidade dos nutrientes para as plantas forrageiras. A produção de perfilhos, que pode ser controlada pela disponibilidade do $\mathrm{N} \mathrm{e}$, em menor escala, pelo fósforo e o potássio, acentua o aparecimento de folhas no perfilho, favorecendo maior interceptação de luz. O tamanho da folha é também importante, mas em algumas espécies é inversamente proporcional à taxa de aparecimento, sendo observadas variações entre e dentro de espécies (HUME, 1991). Em ambiente uniforme, a taxa de aparecimento de folhas é considerada 
COSTA, N.L. et al. Estimativa do rendimento potencial de azevém anual (Lolium multiflorum Lam.) através de modelos matemáticos. PUBVET, Londrina, V. 5, N. 9, Ed. 156, Art. 1051, 2011.

constante, porém é amplamente influenciada por mudanças estacionais, que podem ser causadas pela disponibilidade de água e nutrientes no solo.

Em sistemas de pastejo, a constante remoção da área foliar previne a máxima absorção de luz por um período extenso, minimizando a competição por este recurso, mas pode diminuir o desenvolvimento das raízes, acentuando a competição por nutrientes. O contrário pode ser esperado em sistemas em que se mantém constante a área foliar. Stobbs (1975) verificou que doses crescentes de $\mathrm{N}$ mineral aplicados em Setaria anceps cv. Kazungula aumentaram a produção de MS total e de folhas, particularmente nas camadas superiores do dossel. Pearse e William (1984) avaliando o efeito do intervalo de cortes e doses de adubação nitrogenada em azevém perene constataram o favorecimento da produção de primórdios foliares com a aplicação de N. A taxa de alongamento foliar aumentou de 4,2 para 12,1 mm/perfilho.dia, em resposta à adição de $132 \mathrm{~kg} / \mathrm{ha}$ de $\mathrm{N}$. Davies (1971) verificou que o aparecimento de folhas nessa espécie foi bastante influenciado pela dose de $\mathrm{N}$ aplicado. Segundo Mazzanti et al. (1994), quando se aumenta a dose de $\mathrm{N}$ aplicada, sem o conseqüente ajuste da pressão de pastejo, no caso de lotação contínua ou de diminuição no intervalo de descanso em lotação intermitente, pode-se estar permitindo aumento exagerado da senescência, acúmulo de material morto e queda na taxa de crescimento da pastagem Em geral, ocorre diminuição na duração da vida da folha em alta disponibilidade de $\mathrm{N}$, em função da competição por luz, determinada pelo aumento da taxa de alongamento foliar e pelo maior tamanho final das folhas, assim, os resultados de decréscimo na duração da vida da folha com as doses de $\mathrm{N}$ são explicados pela maior renovação de tecidos em plantas adubadas. Os primórdios foliares de azevém perene ( $L$. perenne L.) quando estabelecido em solo com condição hídrica adequada e fertilização nitrogenada, passaram a se expandir rapidamente, aumentando o número de folhas vivas/perfilho (MAZZANTI, 1997). Blombäck e Eckersten (1997) simulando o crescimento e a dinâmica de $\mathrm{N}$ em azevém perene, constataram que o efeito combinado de baixas 
COSTA, N.L. et al. Estimativa do rendimento potencial de azevém anual (Lolium multiflorum Lam.) através de modelos matemáticos. PUBVET, Londrina, V. 5, N. 9, Ed. 156, Art. 1051, 2011.

temperaturas e disponibilidade de $\mathrm{N}$ reduziram o crescimento potencial da gramínea em até $80 \%$, limitando a maximização da radiação solar interceptada. $\mathrm{O}$ estresse de $\mathrm{N}$ isoladamente, contribuiu para a redução do crescimento em $50 \%$, sendo este o principal fator de redução.

\subsection{Morfogênese e acúmulo de forragem}

A produtividade de forragem e a estrutura do pasto são dependentes da densidade de perfilhos existente e da quantidade de massa acumulada em cada perfilho individual (DIFANTE, 2003). Com o desenvolvimento de folhas e perfilhos, a planta gera área foliar para interceptação de luz e, conseqüentemente, realização de fotossíntese para produção de fotoassimilados e continuação do crescimento (GOMIDE et al., 2006). Hodgson (1990) descreveu o processo de acúmulo de forragem como sendo o resultado líquido do balanço entre o crescimento (produção de novos tecidos - folhas e pseudocolmo) e senescência. Para plantas sob pastejo considera-se o acúmulo líquido entre o crescimento, senescência e o material consumido pelos herbívoros em pastejo (BIRCHMAN; HODGSON, 1983). No estádio vegetativo, o aumento no número de perfilhos é o principal componente de produção de forragem, já no estádio reprodutivo, quando o surgimento de novos perfilhos cessa, o aumento da produção de forragem se dá por meio do aumento do peso dos perfilhos existentes (LOPES, 2003). A massa acumulada no perfilho é dependente de suas características morfogênicas (NABINGER; PONTES, 2001), as quais embora determinadas geneticamente, sofrem influência de fatores ambientais como temperatura, luz, suprimento de nutrientes e condições hídricas do solo (LEMAIRE; CHAPMAN, 1996).

A morfogênese define a dinâmica de geração e expansão da forma da planta no espaço, descrevendo as taxas de aparecimento e expansão de novos órgãos de plantas, assim como seu desaparecimento pela senescência (LEMAIRE; 
COSTA, N.L. et al. Estimativa do rendimento potencial de azevém anual (Lolium multiflorum Lam.) através de modelos matemáticos. PUBVET, Londrina, V. 5, N. 9, Ed. 156, Art. 1051, 2011.

CHAPMAN, 1996; LEMAIRE; AGNUSDEI, 2000). A morfogênese fornece informações detalhadas do crescimento vegetal auxiliando na compreensão dos processos de crescimento das forrageiras, constituindo o primeiro passo para a definição de estratégias racionais do manejo de pastagens (GOMIDE et al., 2006). Para gramíneas em estádio vegetativo, a morfogênese pode ser descrita por três características principais: taxa de aparecimento foliar (TAF), taxa de expansão foliar (TEF) e duração de vida das folhas (DVF) (LEMAIRE; CHAPMAN, 1996).

A TAF foliar refere-se ao número de folhas surgidas em um perfilho por unidade de tempo. Seu valor inverso, o filocrono, representa o intervalo de tempo transcorrido entre o surgimento de duas folhas consecutivas, que geralmente é expresso em graus-dias (GD) (DIFANTE, 2003). Ela desempenha um papel central na morfogênese, e por conseqüência, no IAF, pois influencia diretamente cada um dos três componentes da estrutura da pastagem: tamanho de folha, densidade populacional de perfilhos e número de folhas por perfilho (LEMAIRE; CHAPMAN, 1996). A TAF responde imediatamente a qualquer mudança de temperatura percebida pelo meristema apical (STODDART et al., 1986), e para gramíneas de estação fria sofre pequena influência do nível de nutrição nitrogenada (LEMAIRE, 1988). Apesar do filocrono ser relativamente constante para um dado genótipo, em determinado ambiente, variações dentro de uma mesma espécie e cultivar são possíveis e necessitam ser conhecidas para que esse indicador possa ser usado em decisões de manejo ou para comparar materiais (NABINGER, 1997). A TAF pode ser influenciada pelo padrão de desfolhação, especialmente quando ele está relacionado à alterações na altura do dossel, bem como pela TEF e do comprimento do pseudocolmo, o qual determina a distância que a folha percorre para emergir (GRANT et al., 1988).

A TEF representa o efeito cumulativo da divisão e alongamento celular (SCHNYDER et al., 2000), sendo a variável morfogênica que, isoladamente, mais se correlaciona com a produtividade de forragem (HORST et al., 1978) e muito influenciada por radiação, temperatura e níveis de umidade e nutrientes no solo, 
COSTA, N.L. et al. Estimativa do rendimento potencial de azevém anual (Lolium multiflorum Lam.) através de modelos matemáticos. PUBVET, Londrina, V. 5, N. 9, Ed. 156, Art. 1051, 2011.

notadamente o N. Para Gastal e Nelson (1994) o efeito do N sobre a TEF decorre do maior acúmulo desse nutriente na zona de divisão celular. Quadros e Bandinelli (2005) observaram valores semelhantes de TEF de azevém anual quando adubado com 100 e $200 \mathrm{~kg} / \mathrm{ha}$ de $\mathrm{N}$ e valores superiores quando a adubação nitrogenada correspondeu a $300 \mathrm{~kg} / \mathrm{ha}$. Pontes et al. (2003) observaram efeito da intensidade de pastejo sobre a TEF, registrando um aumento de 0,0026 cm/GD para cada $\mathrm{cm}$ adicional na altura do dossel, o que foi atribuído aos valores superiores de forragem e material senescente nos pastagens com maiores alturas, o que teria proporcionado uma maior remobilização de $\mathrm{N}$.

O efeito da desfolha sobre a taxa de elongação foliar parece estar mais relacionado à interação da intensidade de desfolha com a disponibilidade de compostos orgânicos para recomposição da área foliar (DIFANTE, 2003). A TEF praticamente não sofre influência de uma desfolhação que remova apenas duas a três folhas por perfilho, mas é diminuída em torno de 15 a 20\% quando todas as folhas de um perfilho são removidas (DAVIES, 1974). Schnyder et al. (2000) relataram que desfolhas freqüentes levam a uma forte redução da taxa de elongação foliar. Depois que a folha em elongação atinge seu tamanho final ela permanece verde por um determinado período, o qual representa o teto potencial de rendimento da espécie e é um indicador fundamental para a determinação da intensidade e freqüência de pastejo que permita manter um IAF próximo da maior eficiência de interceptação e máximas taxas de acúmulo de MS (NABINGER; PONTES, 2001). A combinação das características morfogênicas determina as três principais características estruturais do relvado: número de folhas verdes, tamanho de folha e densidade populacional de perfilhos.

O número de folhas verdes é o produto entre a DVF e a TAF. Para uma dada espécie, é uma característica genotipicamente estável na ausência de deficiências hídricas ou nutricionais. O tamanho da folha é o produto da taxa de elongação foliar e o período de elongação de uma folha e, os fatores determinantes do 
COSTA, N.L. et al. Estimativa do rendimento potencial de azevém anual (Lolium multiflorum Lam.) através de modelos matemáticos. PUBVET, Londrina, V. 5, N. 9, Ed. 156, Art. 1051, 2011.

tamanho da folhas são a taxa de elongação e aparecimento foliar (LEMAIRE; CHAPMAN, 1996; LEMAIRE, 1997). Davies et al. (1989) relacionam o tamanho da folha com a altura da bainha, quanto maior seu comprimento, maior será a fase de multiplicação celular, mais tempo a folha que está em elongação ficará protegida pela bainha da luz direta. A densidade populacional de perfilhos é função do equilíbrio entre as taxas de aparecimento e senescência dos perfilhos, sendo diretamente influenciada pela TAF, o que determina o número potencial de sítios para o surgimento de novos perfilhos. Nutrição mineral, manejo de cortes ou pastejo e fatores ambientais, como luz, temperatura, fotoperíodo e disponibilidade hídrica têm grandes efeitos sobre o perfilhamento da planta (OLIVEIRA, 1999).

O produto dessas três características estruturais determina o IAF da pastagem (NABINGER; PONTES, 2001) que, por sua vez, influencia diretamente a capacidade de interceptação luminosa da planta promovendo mudanças tanto nas características morfogênicas, quanto estruturais do dossel (LEMAIRE; CHAPMAN, 1996). A morfogênese auxilia na compreensão do crescimento das gramíneas forrageiras, no entanto permitem avaliá-lo apenas em nível de perfilho individual. Utilizando as medidas morfogênicas e estruturais do pasto, obtidas por meio da técnica de perfilhos marcados, é possível estimar os fluxos de tecido foliar das gramíneas, tanto em nível de perfilho, quanto em nível de área e assim analisar de forma mais abrangente suas respostas ao manejo imposto. O fluxo de biomassa aérea se mostra adequado para estimar o crescimento, consumo e senescência foliar desde que: a) a freqüência das medidas seja ajustada aos ritmos de crescimento e desfolha; b) as amostras sejam representativas da população de plantas e, c) a conversão das medidas de comprimento e área para peso não seja demasiadamente afetada pelos erros devido às variações na densidade de plantas (CARRÈRE et al., 1997). Além disso, como a produção de tecidos foliares é um processo contínuo, regulado por características ambientais e atributos da pastagem (LEMAIRE; AGNUSDEI, 2000) e as lâminas foliares 
COSTA, N.L. et al. Estimativa do rendimento potencial de azevém anual (Lolium multiflorum Lam.) através de modelos matemáticos. PUBVET, Londrina, V. 5, N. 9, Ed. 156, Art. 1051, 2011.

constituem o componente estrutural da pastagem preferencialmente selecionado pelos animais (HENDRICKSEN; MINSON, 1980), a avaliação dos fluxos de tecido foliar também pode contribuir na compreensão das interações planta-animal em sistemas de pastejo (BIRCHAM; HODGSON, 1983).

\subsection{Manejo e Utilização da Pastagem}

As plantas forrageiras apresentam duas características principais que as tornam extremamente viáveis para a exploração pecuária: a sua capacidade de recuperação após o pastejo e o seu valor nutritivo (GOMIDE, 1988). O pastejo é um processo impactante sobre a planta, pois remove suas folhas, elimina os meristemas apicais, reduz a reserva de nutrientes da planta e promove mudanças na alocação de energia e nutrientes da raiz para a parte aérea, a fim de compensar as perdas de tecido fotossintético. Contudo, promove benefícios às plantas pelo aumento da penetração da luz dentro do dossel, alterando a proporção de folhas novas, fotossinteticamente mais ativas, pela remoção de folhas velhas e ativação dos meristemas dormentes na base do caule e rizomas (KEPHART et al., 1995). A habilidade das plantas em sobreviver e crescer sob pastejo decorre de dois mecanismos: escape e tolerância (BRISKE, 1991). O primeiro envolve mecanismos para reduzir e evitar a severidade da desfolha e 0 segundo mecanismos para promover crescimento sob condições de desfolha (BRISKE; RICHARDS, 1995). Os mecanismos de escape são constituídos de atributos da arquitetura da planta, dissuasão mecânica e compostos bioquímicos que reduzem a acessibilidade e palatabilidade dos tecidos da planta, enquanto que os de tolerância constituem-se de processos fisiológicos capazes de promover o crescimento após desfolha (BRISKE, 1996).

A intensidade de pastejo determina a amplitude das respostas plásticas que as plantas têm que desenvolver e a escala de tempo que dispõem para adaptarse a mudanças no ambiente, podendo ser mensurado através do IAF 
COSTA, N.L. et al. Estimativa do rendimento potencial de azevém anual (Lolium multiflorum Lam.) através de modelos matemáticos. PUBVET, Londrina, V. 5, N. 9, Ed. 156, Art. 1051, 2011.

remanescente (DIFANTE, 2003). O pastejo afeta a fisiologia das plantas desfolhadas e exerce um efeito indireto na modificação do micro-ambiente das plantas vizinhas (CAVALCANTE, 2001). Desfolhas intensas induzem a menor eficiência fotossintética inicial das folhas, sendo o tempo diretamente proporcional à sua severidade (BROUGHAM, 1956). Quanto maior a intensidade de pastejo, menor é a taxa inicial de rebrota e maior é o tempo necessário para que a planta atinja sua máxima eficiência fotossintética e sua máxima taxa de crescimento (PARSONS et al., 1988). A adoção de diferentes intensidades de pastejo promove modificações na estrutura da pastagem. Hodgson (1981) constatou que incrementos na intensidade de sua desfolha resultavam em pastagens de azevém com estrutura mais prostrada, o que pode contribuir para a prevenção do alongamento dos entrenós, aumentando a relação folha:colmo (GOMIDE; GOMIDE, 1999, 2001).

A freqüência de pastejo também interfere na estrutura subseqüente do pastagem. Sob desfolhas freqüentes há pouca competição por luz, as plantas podem desenvolver uma resposta fotomorfogênica em resposta a um micro-clima com altas intensidades luminosas (LEMAIRE, 1997, 2001), nessa situação, as plantas desenvolvem folhas pequenas e alta densidade populacional de perfilhos (MAZZANTI; LEMAIRE, 1994). Sob baixa freqüência de desfolha, a competição por luz aumenta durante o período de rebrota e as plantas desenvolvem folhas maiores e pequena densidade populacional de perfilhos (LEMAIRE, 2001). O padrão de desfolha depende primariamente do método de pastejo empregado. A intensidade de desfolha é diretamente dependente da taxa de lotação e da duração do período de pastejo, ambos determinados pelo método de manejo. 0 pastejo contínuo cria uma situação onde o processo de desfolhação é lento o suficiente para permitir uma simultânea reconstituição da camada pastejada enquanto que, em pastejos rotativos, os processos de desfolha e rebrota são mais claramente separados no tempo e distinguíveis (LEMAIRE; CHAPMAN, 1996). 

através de modelos matemáticos. PUBVET, Londrina, V. 5, N. 9, Ed. 156, Art. 1051, 2011.

A utilização da forragem pode ser analisada em termos de balanço entre o seu crescimento e o consumo pelos herbívoros em pastejo (LEMAIRE; CHAPMAN, 1996). A eficiência de utilização da forragem, em sistemas de pastejo, corresponde a proporção de forragem disponível que é consumida pelos animais antes que se inicie o processo de senescência. A otimização da eficiência de utilização da pastagem requer o conhecimento da DVF e a compreensão dos fatores que influenciam a severidade de desfolhação (HODGSON, 1990; LEMAIRE; CHAPMAN, 1996). No pastejo contínuo há um conflito entre a manutenção de altas taxas de crescimento, associada a elevados índices de área foliar, e a maximização da forragem consumida, decorrente da utilização de altas taxa de lotação e maior freqüência de desfolha. Na resolução desse impasse, a manutenção de um IAF entre 2 e 4, em sistemas rotacionados, permitiu o equilíbrio entre esses dois objetivos, sendo as rotações realizadas no momento em que o acúmulo líquido de forragem eram máximos (LEMAIRE; CHAPMAN, 1996). Para pastagens manejadas sob lotação intermitente, uma maior intensidade de pastejo contribui diretamente para uma utilização mais eficiente da colheita de forragem disponível e, indiretamente, para a redução nas perdas por senescência e morte de tecidos no período de rebrota, contudo há uma redução na eficiência de utilização, ou seja, produto animal produzido por unidade de forragem acumulada por área, o que introduz o conceito de conversão da forragem ingerida em produto animal (HODGSON, 1979; GOMIDE; GOMIDE, 1999).

\section{Mudanças no sistema de manejo empregado}

Para a obtenção do potencial de rendimento das pastagens torna-se importante a avaliação de sistemas de produção, onde seja explorada a capacidade de perfilhamento da planta, concomitantemente com a combinação entre a quantidade de forragem e a exigência nutricional do animal. A utilização 
COSTA, N.L. et al. Estimativa do rendimento potencial de azevém anual (Lolium multiflorum Lam.) através de modelos matemáticos. PUBVET, Londrina, V. 5, N. 9, Ed. 156, Art. 1051, 2011.

intensiva de pastagens demanda uma nova concepção sobre os princípios básicos que direcionam o seu manejo. Apesar da importância dos fatores abióticos sobre os processos de acúmulo e senescência de forragem, a adoção de práticas de manejo que maximizem as potencialidades dos recursos naturais assume papel relevante para assegurar a produtividade, longevidade e economicidade da produção animal em pastagem.

O manejo da pastagem baseado no conceito de IAF crítico, condição na qual 95\% da radiação incidente são interceptadas pelo dossel da pastagem, fornece as ferramentas essenciais para a compreensão dos processos de acúmulo e senescência da forragem, notadamente de folhas, as quais são altamente correlacionadas com o valor nutritivo, representado pela taxa de consumo, digestibilidade e natureza dos produtos da digestão. A manutenção de um IAF muito alto na pastagem incorrerá na perda do potencial de produção que limitará a utilização de forragem, independentemente da eficiência de utilização (LEMAIRE; CHAPMAN, 1996). Semelhantemente, a taxa de consumo de forragem, bem como a eficiência de sua utilização tende a decrescer, como resultado de uma redução na densidade populacional de perfilhos e menor relação folha:colmo (HODGSON, 1979). Apesar da busca por maior eficiência de utilização da forragem, as perdas por senescência são inevitáveis, em função da necessidade de priorizar a produção por animal, o que torna necessária a adoção de ofertas de forragem acima da capacidade de ingestão dos animais, de modo a maximizar o efeito seletivo dos animais (NABINGER, 1996).

O manejo do pastejo afeta significativamente a produtividade animal. Pontes et al. (2004), ao estudar os fluxos de biomassa foliar em azevém anual manejado em diferentes alturas (5, 10, 15 e $20 \mathrm{~cm}$ ), observaram que 0 desempenho de borregos inteiros sofreu influência da altura do dossel, sendo os melhores ganhos, tanto individuais como por área, observados quando o pasto foi mantido com altura entre 10 e $15 \mathrm{~cm}$. Canto et al. (1999) e Roman et al. (2007) observaram aumento linear no ganho médio diário de peso de cordeiros e 
COSTA, N.L. et al. Estimativa do rendimento potencial de azevém anual (Lolium multiflorum Lam.) através de modelos matemáticos. PUBVET, Londrina, V. 5, N. 9, Ed. 156, Art. 1051, 2011.

borregas, respectivamente, com o aumento da disponibilidade de forragem do azevém. As variações no desempenho de ovinos, possivelmente foram relacionadas a variações na estrutura das plantas da gramínea, em função das diferentes intensidades de pastejo. A utilização de intensidades de desfolha mais severas provoca alterações nas características morfogênicas e estruturais do azevém, diminuindo o aproveitamento dos recursos ambientais para produção de forragem (PONTES et al., 2003; BARBOSA et al, 2010). Deste modo, a imposição de práticas de manejo baseada na altura das plantas, para a entrada e saída dos animais, pode incorrer em baixa eficiência do processo de pastejo, pois desconsidera os princípios morfológicos e fisiológicos que condicionam a produção de forragem e o seu consumo pelos animais (SILVA; NASCIMENTO JÚNIOR, 2007).

A maior compreensão dos mecanismos que compõem o processo de seleção e consumo de forragem, representados pela taxa de ingestão (taxa, massa, profundidade e área do bocado) e o tempo de pastejo, tornou possível a imposição de práticas de manejo de pastagens, considerando-se o comportamento animal. A altura da pastagem como indicador para o adequado manejo da pastagem deve estar associada à estrutura e disposição das plantas na paisagem, a qual refletirá o grau de acessibilidade da forragem disponível aos animais. Os fatores que controlam o número, a duração das refeições e o tempo da estação alimentar, em relação ao estado da pastagem, são mecanismos importantes para predizer a aquisição de nutrientes pelos animais em pastejo (BAUMONT et al., 2000, 2004; CARVALHO, 2005). No entanto, essa concepção contraria os objetivos precípuos de antigos modelos de pesquisa, em que a prioridade é comumente focada na produtividade dos sistemas, enquanto que aspectos como comportamento animal, qualidade do produto final e questões ambientais são totalmente negligenciadas. A qualidade de um ambiente pastoril adequado sob o do ponto de vista alimentar (ingestão de nutrientes) pode ser avaliada por um conjunto de respostas comportamentais: (i) em situações de 
COSTA, N.L. et al. Estimativa do rendimento potencial de azevém anual (Lolium multiflorum Lam.) através de modelos matemáticos. PUBVET, Londrina, V. 5, N. 9, Ed. 156, Art. 1051, 2011.

elevado nível de alimentação os animais escolhem poucas estações alimentares enquanto passam bastante tempo explorando-as; (ii) o deslocamento entre as estações alimentares pode ser longo; (iii) o número de refeições é maior e a duração das refeições é menor; (iv) o intervalo entre refeições é maior; (v) menor é o tempo de pastejo (CARVALHO; MORAES, 2005).

\section{Considerações Finais}

A utilização de modelos matemáticos para a predição do rendimento potencial de gramíneas forrageiras é uma ferramenta útil e viável, além de fornecer respostas às questões científicas, agronômicas e de planejamento, auxilia no entendimento sobre as interações genéticas, fisiológicas e do ambiente. Desta forma, torna-se possível a avaliação de estratégias mais adequadas para cada condição específica, facilitando a tomada de decisões sobre as práticas de manejo a serem adotadas, de modo a maximizar a produção de forragem em sistemas pastoris.

As discrepâncias constatadas entre as estimativas dos diferentes modelos decorrem da robustez dos parâmetros considerados em expressar de forma fidedigna a natureza abiótica e fisiológica dos fenômenos envolvidos no processo de acúmulo e senescência de biomassa. A diferença entre o rendimento potencial e o comumente observado em sistemas reais de produção fornece a dimensão das perdas por estresses ambientais e biológicos que afetam a produtividade das pastagens, permitindo intervenções que amenizem seus efeitos limitantes.

\section{Referências Bibliográficas}

BAHMANI, I.; HAZARD, L.; VARLET-GRANCHER, C. et al. Differences in tillering of long- and shortleaved perennial ryegrass genetic lines under full light and shade treatments. Crop Science, v.40, p.1095-1102, 2000..

BARBOSA, C.M.P.; CARVALHO, P.C.F.; CAUDURO, G.F. et al. Componentes do processo de pastejo de cordeiros em azevém sob diferentes intensidades e métodos. Archivos de Zootecnia, v.59, n.225, p.39-50, 2010. 
COSTA, N.L. et al. Estimativa do rendimento potencial de azevém anual (Lolium multiflorum Lam.) através de modelos matemáticos. PUBVET, Londrina, V. 5, N. 9, Ed. 156, Art. 1051, 2011.

BARBOSA, C.M.P.; CARVALHO, P.C.F.; CAUDURO, G.F. et al. Terminação de cordeiros em pastagens de azevém anual manejadas em diferentes intensidades e métodos de pastejo Revista Brasileira de Zootecnia, v.36, n.6, p.1953-1960, 2007.

BAUMONT, R.; COHEN-SALMON, D. et al. A mechanistic model of intake and grazing behaviour in sheep integrating sward architecture and animal decisions. Animal Feed Science Technology, v.112, p.5-28, 2004.

BAUMONT, R.; PRACHE, S.; MEURET, M. How forage characteristics influence behaviour and intake in small ruminants: a review. Livestock Production Science, v.64, p.15-28, 2000.

BIRCHAM, J.S., HODGSON, J. The influence of sward condition on rates of herbage growth and senescence in mixed swards under continuous stocking management. Grass and Forage Scince, v.38, p.323-331, 1983.

BISCOE, P.V.; SCOTT, R.K.; MONTEIH, J.L. Barley and its environment. III. Carbon budget of the stand. Journal of Applied Ecology, v.12, p.269-293, 1975.

BLOMBÄCK, K.; ECKERSTEN, H. Simulated growth and nitrogen dynamics of a perennial rye grass. Agricultural and Forest Meteorology. v. 88, p.37-45. 1997.

BONHOMME, R. Beware of comparing RUE values calculated from PAR vs. solar radiation or absorbed vs. intercepted radiation. Field Crops Research, v.68, p.247-252, 2000.

BOOTE, K.J.; JONE, J.W.; PICKERING, N.B. Potential uses and limitations of crop models. Agronomy Journal, v.88, p.704-716, 1996.

BRISKE, D.D. Developmental morphology and physiology of grasses. In: HEITSCHIMIDT, R.K.; STUTH, J.W. (Ed.) Grazing management: an ecological perspective. Portland: Timber press, 1991. p.85-108.

BRISKE, D.D, Strategies of plant survival in grazed systems: a functional interpretation. In: HODGSON, J.; ILLIUS, A.W. (Eds.) The ecology and management of grazing systems. Guilford: CAB International, 1996. p.37-67.

BRISKE, D.D.; RICHARDS, J.H. Plant responses to defoliation: a physiological, morphological and demographic evaluation. In: BEDUNAH, D.J.; SOSEBEE, R.E. (Eds.). Wildland Plants: physiological geology and developmental morphology. Society for Range Management. Denver, Colorado, 1995. p.635-710.

BROUGHAM, R. W. Effect of intensity of defoliation on regrowth of pasture. Australian Journal of Agricultural Research, v.7, n.5, p.377-387, 1956.

CANTO, M.W.; MOOJEN, E.L.; CARVALHO, P.C.F. et al. Produção de cordeiros em pastagem de azevém e trevo branco sob diferentes níveis de resíduos de forragem. Pesquisa Agropecuária Brasileira, Brasília, v.34, n.2, p.309-316, 1999.

CARRÈRE, P.; LOUAULT, F.; SOUSSANA, J.F. Tissue turnover within grass-clover mixed swards grazed by sheep. Methodology for calculating growth, senescence and intake fluxes. Journal of Applied Ecology, v.34, p.333-348, 1997. 
COSTA, N.L. et al. Estimativa do rendimento potencial de azevém anual (Lolium multiflorum Lam.) através de modelos matemáticos. PUBVET, Londrina, V. 5, N. 9, Ed. 156, Art. 1051, 2011.

CARVALHO, P.C.F. O manejo da pastagem como gerador de ambientes pastoris adequados à produção animal. In: PEDREIRA, C.G.S.; MOURA, J.C.; SILVA, S.C. da; FARIA, V.P. de (Eds.). Teoria e prática da produção animal em pastagens. Piracicaba: FEALQ, 2005, p.7-32.

CARVALHO, P.C.F.; MORAES, A. Comportamento ingestivo de ruminantes: bases para o manejo sustentável do pasto. In: CECATO, U.; JOBIM, C.C. Manejo sustentável em pastagem. Maringá: UEM, 2005, v.1, p.1-20.

CARVALHO, P.C.F.; ROCHA, L.M.; BAGGIO, C. et al. Característica produtiva e estruturas de pastos msitos de aveia e azevém manejados em quatro alturas sob lotação contínua. Revista Brasileira de Zootecnia, v.39, n.9, p.1857-1865, 2010.

CAUDURO, G.F.; CARVALHO, P.C.F.; BARBOSA, C.M.P. et al. Variáveis morfogênicas e estruturais de azevém anual (Lolium multiflorum Lam.) manejado sob diferentes intensidades e métodos de pastejo. Revista Brasileira de Zootecnia, v.35, n.4, p.1298-1307, 2006.

CAVALCANTE, M.A.B. Compilação dos artigos: Ecofisiologia de pastagens: aspectos da dinâmica das populações de plantas forrageiras em relvados pastejados (Lemaire, 2001) e A fisiologia do crescimento de gramíneas sob pastejo: fluxo de tecidos (Lemaire, 1997). Viçosa: UFV, 2001. Disponível em:<http:www.forragicultura.com.br/>. Acesso em: 12 out. 2010.

CHAPIN, F.S.; BLOOM, A.J.; FIELD, C.B. et al. Plant response to multiple environmental factors. BioScience, v.37, p.49-57, 1987.

COSTA, L.C.; MORISON, J.I.L.; DENNET, M.D. Carbon balance of growing faba bean and its effect on crop growth: experimental and modeling approaches. Revista Brasileira de Agrometeorologia, v.4, p.11-17, 1996.

DAVIES, A. Leaf tissue remaining after cutting and regrowth in perennial ryegrass. Journal of Agricultural Science, v.82, p.165-172, 1974.

DAVIES, A. Changes in growth rate and morphology of perennial ryegrass swards at high and low nitrogen levels. Journal of Agricultural Science, v.77, p.123-134, 1971.

DAVIES, D.A.; FOTHERGILL, M.; JONES, D. Frequency of stocking rate required on contrasting upland perennial ryegrass pastures continuously grazed to a sward height criterion from May to July. Grass and Forage Science, v.44, p.213-221, 1989.

DIAS FILHO; M. B. Efeito do estresse hídrico em alguns aspectos agronômicos e fisiológicos do capim Tobiatã (Panicum maximum Jacq. cv. Tobiatã) em casa de vegetação. Piracicaba: ESALQ, 1996, 103p. Dissertação de Mestrado.

DIFANTE, G.S. Importância da morfogênese no manejo de gramíneas forrageiras. Viçosa: UFV, 30p. 2003.

DOORENBOS, J.; KASSAM, A.H. Efeito da água no rendimento das culturas. Campina Grande: UFPB, 1994. 306p. (Estudos FAO: Irrigação e Drenagem, 33).

DOURADO NETO, D.; TERUEL, D.A.; REICHARDT, K. et al. Principles of crop modeling and simulation: I. Uses of mathematical models in agricultural science. Scientia Agricola, v.55, p.46$50,1998$. 
COSTA, N.L. et al. Estimativa do rendimento potencial de azevém anual (Lolium multiflorum Lam.) através de modelos matemáticos. PUBVET, Londrina, V. 5, N. 9, Ed. 156, Art. 1051, 2011.

EMBRAPA. EMPRESA BRASILEIRA DE PESQUISA AGROPECUÁRIA. Sistema brasileiro de classificação de solos. Brasília: Embrapa Solos, 1999. 412p. (Documentos, 5).

EVANS, J.R. Nitrogen and photosynthesis in the flag leaf of wheat (Triticum aestivum L.). Plant Physiology, v.72, n.2, p.297-302, 1983.

FERRARIS, R.; MAHONY, M.J.; WOOD, T.T. Effect of temperature and solar radiation on the development of dry matter and attributes of elephant grass (Pennisetum purpureum Schum.). Australian Journal of Agriculture Research, v.37, p.621-632, 1986.

FLORES, R.A.; DALL'AGNOL, M.; NABINGER, C. et al. Produção de forragem de populações de azevém anual no estado do Rio Grande do Sul. Revista Brasileira de Zootecnia, v.37, n.7, p.1168-1175, 2008.

FREITAS, F.A.; OLIVEIRA, A.C.; CARVALHO, F.I.F. et al. Análise multivariada de populações de azevém (Lolium multiflorum L.) em diferentes regimes de água. Revista Brasileira de Agrociência, v.9, n.1, p.17-23, 2003.

GALETI, P.A Conservação do solo, reflorestamento, clima. Campinas: ICEA, 1982. 236p.

GALLAGHER, J.N.; BISCOE, P.V. Radiation absorption, growth and yield of cereals. Journal of Agricultural Science, v.91, p.47-60, 1978.

GASTAL, F.; NELSON, C.J. Nitrogen use within the growing leaf blade of tall fescue. Plant Physiology, v.105, p.191-197, 1994.

GASTAL, F.; BÉlANGER, G.; LEMAIRE, G. A model of the leaf extension rate of tall fescue in reponse to nitrogen and temperature. Annals of Botany, v.70, p.437-442, 1992.

GAUTIER, H.; VARLET-GRANCHER, C.; HAZARD, L. Tillering responses to the light environment and to desfoliation in populations of perennial ryegrass (Lolium perenne L.) selected for contrasting leaf length. Annals of Botany, v.83, p.423-429, 1999.

GOMIDE, J.A. Fisiologia das plantas forrageiras e manejo das pastagens. Informe Agropecuário, v.88, n.153/154, p.11-18, 1988.

GOMIDE, J.A. Morgênese e analise de crescimento de gramineas tropicais. In: SIMPÓSIO INTERNACIONAL DE PRODUÇÃO ANIMAL EM PASTEJO, 1997, Viçosa. Anais... UFV: Viçosa, 1997, p.411-430.

GOMIDE, C.A.M.; GOMIDE, J.A. Análise de crescimento de cultivares de Panicum maximum Jacq. Revista Brasileira de Zootecnia, v.28, n.4, p.675-680, 1999.

GOMIDE, J.A.; GOMIDE, C.A.M. Utilização e manejo de pastagens. In: REUNIÃO ANUAL DA SOCIEDADE BRASILEIRA DE ZOOTECNIA, 38., 2001, Piracicaba. Anais... Piracicaba: FEALQ, 2001. p.808-825.

GOMIDE, A.M.G.; GOMIDE, J.A.; PACIULLO, D.S.C. Morfogênese como ferramenta para o manejo de pastagens. In: REUNIÃO ANUAL DA SOCIEDADE BRASILEIRA DE ZOOTECNIA, 43., 2006, João Pessoa. Anais... João Pessoa, SBZ, 2006. CD-ROM.

GOSSE, G.; CHARTIER. M.; VARLET-GRANCHER. C. et al. Prediction maximale de matière sèche et rayonment solaire intercept par un couvert végètal. Agronomie, v.6, p. 47-58, 1986. 
COSTA, N.L. et al. Estimativa do rendimento potencial de azevém anual (Lolium multiflorum Lam.) através de modelos matemáticos. PUBVET, Londrina, V. 5, N. 9, Ed. 156, Art. 1051, 2011.

GRANT, S.A.; BARTHRAM, G.T.; TORVELL, L.L. et al. Comparison of herbage production under continuous stocking and intermittent grazing. Grass and Forage Science, v.43, n.1, p.29-39, 1988.

GREENWOOD, D.J.; LEMAIRE, G.; GOSSE, G.; CRUZ,P,; DRAYCOTT, A.; NEETESON, J.J. Decline in percentage $\mathrm{N}$ of $\mathrm{C}_{3}$ and $\mathrm{C}_{4}$ crops with increasing plant mass. Annals of Botany. v.66, p.425-436, 1990.

HENDRICKSEN, R.; MINSON, D.J. The intake and grazing behaviour of cattle a crop of Lablab purpureus cv. Rongai. Journal of Agricultural Science, v.95, p.547-554, 1980.

HODGSON, J. Grazing management: science into practice. London: Longman Scientific \& Technical, 1990. 203p.

HODGSON, J. Nomenclature and definitions in grazing studies. Grass and Forage Science, v.34, p.11-18, 1979.

HODGSON, J. Variations in the surface characteristics of the sward and short-term rate of herbage intake by calves and lambs. Grass and Forage Science, v.36, p.49-57, 1981.

HORST, G. L.; NELSON, C. J.; ASAY, K. H. Relationship of leaf elongation to forage yield of tall fescue genotypes. Crop Science, v.18, p.715-719, 1978.

HUME, D.E. Leaf and tiller production of praire grass (Bromus willdenowwii) and two ryegrass (Lolium) species. Annals of Botany, v.67, p.111-121, 1991.

KEPHART, K.D.; WEST, C.P.; WEDIN, D.A. Grassland ecosystems and their improvement. In: BARNES, R.F.; MILLER, D.A.; NELSON, C.J. (Eds). Forages: an introduction to grassland agriculture. Ames: The Science of Grassland Agriculture, Iowa State University Press, 1995. v.1, p.141-153.

LARCHER, W. Physiological plant ecology. Berlin: Spring-Verlag, 1975. 252p.

LEMAIRE, G. Ecophysiology of grasslands: dynamics aspects of forage plant populations in grazed swards. In: INTERNATIONAL GRASSLAND CONGRESS, 19., 2001, São Pedro. Proceedings... São Paulo: ESALQ, 2001, p.29-37.

LEMAIRE, G. Sward dynamics under different management programmes. In: GENERAL MEETING OF THE EUROPEAN GRASSLAND FEDERATION, 12., 1988, Belclare. Proceedings... Belclare: Irish Grassland Association, 1988. p.7-22.

LEMAIRE, G. The physiological of grass growth under grazing: tissue turnover. In: SIMPÓSIO INTERNACIONAL DE PRODUÇÃO ANIMAL EM PASTEJO, 1997, Viçosa. Anais... UFV: Viçosa, 1997, p.117-144.

LEMAIRE, G.; AGNUSDEI, M. Leaf tissue turnover and efficiency of herbage utilization. In: LEMAIRE, G.; HODGSON, J.; MORAES, A. et al. (Eds). Grassland ecophysiology and grazing ecology. London: CAB International, 2000. p.265-288.

LEMAIRE, G.; CHAPMAN. D. Tissue flows in grazed plant communities. In: HODGSON, J.; ILLIUS, A.W. (Eds.) The ecology and management of grazing systems. Wallingford: $C A B$ International, 1996. p.3-36. 
COSTA, N.L. et al. Estimativa do rendimento potencial de azevém anual (Lolium multiflorum Lam.) através de modelos matemáticos. PUBVET, Londrina, V. 5, N. 9, Ed. 156, Art. 1051, 2011.

LEMAIRE, G; SALETTE, J. Relation entre dynamique de croissance et dymamique de prévèment d'azote pour un peuplement de graminées fourragéres. 1. Etude de l'effet du milieu. Agronomie, v.4, p.241-249, 1984.

LOOMIS, R.S.; WILLIAMS, W.A. Maximum crop productivity: an estimate. Crop Science, Madison, v.3, n.1, p.67-72, 1963.

LOPES, B.A. Aspectos importantes da fisiologia vegetal para o manejo. Viçosa: UFV, 2003. Disponível em: <http:www.forragicultura.com.br/>. Acesso em: 12/10/2010.

LUSTOSA, S.B.C. Características estruturais e morfogênese de azevém anual em resposta ao nitrogênio. Curitiba: UFPR, 2002. 64p. Tese de Doutorado em Produção Vegetal.

MAKINO, A.; MAE, T.; OHIRA, K. Relation between nitrogen and ribulose 1,5-biphosphate carboxylase in rice leaves from emergence through senescence. Plant Cell Physical, v.25, p.429-37, 1984.

MARASCHIN, G.E. Manejo de coastcross-1 sob pastejo. In: WORKSHOP SOBRE O POTENCIAL FORRAGEIRO DO GÊNERO CYNODON. 1995, Juiz de Fora. Anais... Juiz de Fora: Embrapa Gado de Leite, 1995. p.93-107.

MATTHEW, C.; ASSUERO, S.G.; BLACK, C.K.; et al. Tiller dynamics of grazed swards. In: LEMAIRE, G.; HODGSON, J.; MORAES, A. et al. (Eds). Grassland ecophysiology and grazing ecology. London: CAB International, 2000. p.127-150.

MATZENAUER, R.; SUTILI, R. A água na cultura do milho. Porto Alegre, Boletim IPAGRo, v.11, n.26, p.17-32, 1983.

MAZZANTI, A. Adaptación de especies forrajeras a la defoliación. In: SIMPÓSIO SOBRE AVALIAÇÃO DE PASTAENS COM ANIMAIS, 1., 1997, Maringá. Anais... Maringá: UEM, p.75-84, 1997.

MAZZANTI, A.; LEMAIRE, G. Effect of nitrogen fertilization upon herbage production of tall fescue sward continuously grazed by sheep. 2. Consumption and efficiency of herbage utilization. Grass and Forage Science, v.49, p.352-359, 1994.

MAZZANTI, A.; LEMAIRE, G.; GASTAL, F. The effect of nitrogen fertilization upon the herbage production of tall fescue swards continuously grazed with sheep. 1. Herbage growth dynamics. Grass and Forage Science, v.49, p.111-120, 1994.

MITTELMANN, A.; CORRÊA, B.O.; KUHN, M.D. et al. Produtividade de acessos de azevém anual (Lolium multiflorum). In: REUNIẪO DO GRUPO TÉCNICO EM FORRAGEIRAS DO CONE SUL, 21., Pelotas, 2005. Anais... Pelotas: UFPel, p.23-35, 2005.

MONTEITH, J.L. Light distribution and photosynthesis in field crops. Annals of Botany, v.29, p.17-37, 1965.

MONTEITH, J.L. Climate and the efficiency of crop production in Britain. Philosophical Transactions of the Royal Society, London, v.281, p.227-294, 1977.

NABINGER, C. Aspectos ecofisiológicos do manejo de pastagens e utilização de modelos como ferramenta de diagnóstico e indicação de necessidades de pesquisa. In: REUNIÃO DO GRUPO TÉCNICO REGIONAL DO CONE SUL (ZONA CAMPOS) EM MELHORAMENTO E UTILIZAÇÃO DE 
COSTA, N.L. et al. Estimativa do rendimento potencial de azevém anual (Lolium multiflorum Lam.) através de modelos matemáticos. PUBVET, Londrina, V. 5, N. 9, Ed. 156, Art. 1051, 2011.

RECURSOS FORRAGEIROS DAS ÁREAS TROPICAL E SUBTROPICAL, 1996, Porto Alegre. Anais... Porto Alegre: UFRGS, 1996. p.17-62.

NABINGER, C. Eficiência do uso de pastagens: disponibilidade e perdas de forragem. In: SIMPÓSIO SOBRE MANEJO DA PASTAGEM, 14., 1997, Piracicaba. Anais... Piracicaba: FEALQ, 1997. p.213-251.

NABINGER, C. Manejo da desfolha. In: SIMPÓSIO SOBRE MANEJO DA PASTAGEM, 19., 2001, Piracicaba. Anais... Piracicaba: ESALQ, 2001. p.192-210.

NABINGER, C.; PONTES, L.S. Morfogênese de plantas forrageiras e estrutura do pasto. In: REUNIÃO ANUAL DA SOCIEDADE BRASILEIRA DE ZOOTECNIA. 38., 2001, Piracicaba. Anais... Piracicaba: SBZ, 2001. 22p. (CD-ROM).

OLIVEIRA, M.A. Morfogênese, análise de crescimento e valor nutritivo do capim Tifton 85 (Cynodon spp.) em diferentes idades de rebrota. Viçosa: UFV, 1999. 94p. Dissertação de Mestrado em Zootecnia.

PARSONS, A.J.; JOHNSON, I.R.; HARVEY, A. Use of a model to optimize the interaction between frequency and severity of intermittent defoliation and to provide a fundamental comparison of the continuous and intermittent defoliation of grass. Grass and Forage Science, v.43, n.1, p.49-59, 1988.

PEARSE, P.J.; WILLIAM, D. Effects of applied nitrogen on grass leaf initiation, development and death in field swards. Journal of Agriculture Science, v.103, p.405-413, 1984.

PELLEGRINI, L.G.; MONTEIRO, A.L.G.; NEUMANN, M. et al. Produção e qualidade de azevémanual submetido a adubação nitrogenada sob pastejo por cordeiros. Revista Brasileira de Zootecnia, v.39, n.9, p.1894-1904, 2010.

PEREIRA, A.R.; MACHADO, E.C. Um simulador dinâmico do crescimento de uma cultura de canade-açúcar. Bragantia, v.45, n.1, p.107-12, 1986.

PEREIRA, A.V.; MITTELMANN, A.; LEDO, F.J.S. et al. Comportamento agronômico de populações de azevém anual (Lolium multiflorum L.) para cultivo invernal na região sudeste. Ciência e Agrotecnologia, v.32, n.2, p.567-572, 2008

PETRY, M. T., CARLESSO R. WOLSCHICK. D. et al. Consumo de água e rendimento de grãos de sorgo granífero cultivado em diferentes classes de solo In: CONGRESSO BRASILEIRO DE ENGENHARIA AGRÍCOLA, 28., Pelotas. 1999. Resumos... Pelotas: SBEA, 1999. 3p.

PLÁ, G.; LOPES, N.F. Estimativa de crescimento e produtividade do feijoeiro pela utilização de modelo matemático-fisiológico. Pesquisa Agropecuária Brasileira, v.33, n.8, p. 286-284, 1998.

PONTES, L.S.; NABINGER, C.; CARVALHO, P.C.F. et al. Variáveis morfogênicas e estruturais de azevém anual (Lolium multiflorum Lam) manejado em diferentes alturas. Revista Brasileira de Zootecnia, v.32, n.4, p.814-820, 2003.

PONTES, L.S.; CARVALHO, P.C.F.; NABINGER, C. et al. Fluxo de biomassa em pastagem de azevém anual (Lolium multiflorum Lam.) manejada em diferentes alturas. Revista Brasileira de Zootecnia, v.33, n.3, p.529-537, 2004. 
COSTA, N.L. et al. Estimativa do rendimento potencial de azevém anual (Lolium multiflorum Lam.) através de modelos matemáticos. PUBVET, Londrina, V. 5, N. 9, Ed. 156, Art. 1051, 2011.

QUADROS, F.L.F.; BANDINELLI, D.G. Efeitos da adubação nitrogenada e de sistemas de manejo sobre a morfogênese de Lolium multiflorum Lam. e Paspalum urviellei Steud. Em ambiente de várzea. Revista Brasileira de Zootecnia, v.34, n.1, p.44-53, 2005.

RESTLE, J.; ROSO, C.; SOARES, A.B. Produção animal e retorno econômico em misturas de gramíneas anuais de estação fria. Revista Brasileira de Zootecnia, v.28, n.2, p.235-243, 1999.

RIBEIRO, T.M.D.; MONTEIRO, A.L.G.; POLI, C.H.E.C. et al. Características da pastagem de azevém e produtividade de cordeiros em pastejo. Revista Brasileira de Zootecnia, v.38, n.3, p.580-587, 2009.

RODRIGUES, L.R.A: RODRIGUES, T.J.D. Ecofisiologia de plantas forrageiras. In: CASTRO, P.R.C; FERREIRA, S.O.; YAMADA, T. (Eds.). Ecofisiologia da produção agrícola Piracicaba: POTAFOS, p.203-230, 1987.

ROMAN, J.; ROCHA, M.G.; PIRES, C.C. et al. Comportamento ingestivo e desempenho de ovinos em pastagem de azevém anual (Lolium multiflorum Lam.) com diferentes massas de forragem. Revista Brasileira de Zootecnia, v.36, n.4, p.780-788, 2007.

RUSSEL, G.; JARVIS, P.G.; MONTEITH, J.L. Absorption of radiation by canopies and stand growth. In: RUSSEL, G.; JARVIS, P.G.; MONTEITH, J.L. (Eds.). Plant canopies: their growth, form and function. Cambridge: Cambridge University, 1989. p.21-39. (Society for Experimental Biology Seminar Series, 31).

SCHNYDER, H.; SCHÄUFELE R.; DE VISSER, R. et al. An integrated view of $C$ and $N$ uses in the leaf growth zones of defoliated grasses. In: LEMAIRE, G.; HODGSON, J.; MORAES, A.; CARVALHO, P. C. F.; NABINGER, C. (Eds.) Grassland Ecophysiology and Grazing Ecology. Wallingford: CABI Publishing, 2000. p.41-60.

SCHÖFFEL, E.R.; VOLPE, C.A. Eficiência de conversão da radiação fotossinteticamente ativa interceptada pela soja para produção de fitomassa. Revista Brasileira de Agrometeorologia, n.2, v.9, p.241-249, 2001.

SHIBLES, R.M.; WEBER, C.R. Interception of solar radiation and dry matter production by various soybean planting patterns. Crop Science, v.6, p.55-59, 1966.

SHIBLES, R.M.; WEBER, C.R. Leaf area, solar radiation interception, and dry matter production by various soybean planting patterns. Crop Science, v.6, p.575-577, 1965.

SINCLAIR, T.R. Limits to crop yield? In: BOOTE, K.J. (Ed.). Physiology and determination of crop yield. Madison: American Society of Agronomy/Crop Science Society of America/Soil Science Society of America, 1994. p.509-532.

SINCLAIR, T.R. Crop yield potential and fairy tales. In: BUXTON, D.R. et al. (Ed). International Crop Science I. Crop Science Society of America, 1993. Cap.52, p.707-711.

SILVA JÚNIOR, L.C.; SILVA, W.J.; BISINOTTO, F.F. Efeito da radiação fotossinteticamente ativa no crescimento e desenvolvimento de gramíneas forrageiras. Belo Horizonte: EPAMIG, 2009, 4p.

SILVA, M.G. Modelos agropecuários: enfoque de sistemas en la investigación genadera. Santiago: IICA, 80p. 1980. 
COSTA, N.L. et al. Estimativa do rendimento potencial de azevém anual (Lolium multiflorum Lam.) através de modelos matemáticos. PUBVET, Londrina, V. 5, N. 9, Ed. 156, Art. 1051, 2011.

SILVA, S.C.; NASCIMENTO JÚNIOR, D. Avanços na pesquisa com plantas forrageiras tropicais em pastagens: características morfofisiológicas e manejo do pastejo. Revista Brasileira de Zootecnia, v.36, p.121-138, 2007.

SIVAKUMAR, M.V.K.; VIRMANI, S.M. Crop productivity in relation to interception of photosynthetically active radiation. Agricultural and Forest Meteorology, v.31, n.1, p.131$141,1984$.

SOARES, A.B. Produção animal em pastagem de triticale (Xtriticosecale) mais azevém (Lolium multiflorum Lam.) submetida a níveis de adubação nitrogenada. Santa Maria: UFSM, 189p. 1999. Dissertação de Mestrado.

STOBBS, T.H. The effect of plant structure on the intake nitrogen on the size of bite harvested by Jerssey cows grazing Setaria anceps cv. Kazungula swards. Australian Journal of Agriculture Research, v.24, p.997-1007, 1975.

STODDART, J.L.; THOMAS, H.; LLOYD, E.J. et al. The use of a temperature- profiled position transducer for the study of low-temperature growth in Gramineae. Planta, v.167, p.359-363, 1986.

TAIZ, L.; ZEIGER, E. Fisiologia Vegetal. Porto Alegre: Artmed, 3.ed., 2004. 719p.

TIESZEN, L.L.; DETLING, J.K. Productivity of grassland and tundra. Berlin: Springer-Verlag, V.12, 1983, p.173-203

VAN SOEST, P.J. Nutritional ecology of the ruminant. New York: Comstock Publishing, 1994. 476p.

VARLET-GRANCHER, C.; GOSSE, G.; CHARTIER, M. et al. Mise au point: rayonnement solaire absorbé ou intercepté par un couvert végétal. Agronomie, v.9, p.419-439, 1989.

WHITHEMAN, P.C. Tropical pasture science. New York: Oxford University Press, 1980. 392p.

WILSON, J.R. Environmental and nutritional factors affecting herbage quality. In: HACKER, J.B. (Ed.). Nutritional limits to animal production from pastures. Farnham: CAB, 1982. p.111131. 